\title{
Hydrogen evolution and absorption phenomena in plasma membrane of higher plants
}

Xin Zhang ${ }^{1,2}$, Zhao Zhang ${ }^{1,2}$, Zehua Su, ${ }^{1,2}$, Qinghui Zhao ${ }^{1,2}$, Tyler W. LeBaron ${ }^{3}$, Qinjian $\mathrm{Li}^{1,2}$, Baobei Lyu ${ }^{1,2}$, Yao Mawulikplimi Adzavon ${ }^{1,2}$, Guangyang Liu ${ }^{4}$, Mengyu Liu ${ }^{1,2}$, Fei Xie $^{1,2}$, Pengxiang Zhao ${ }^{1 * *} \&$ Xuemei Ma ${ }^{1}$.

${ }^{1}$ College of Life Science and Bioengineering, Beijing University of Technology, Beijing 100124, P. R. China;

${ }^{2}$ Beijing molecular hydrogen research center, Beijing 100124, P. R. China;

${ }^{3}$ Molecular Hydrogen Institute. Utah, USA;

${ }^{4}$ Department of Stem Cell Biology \& Regenerative Medicine, Yi-Chuang Institute of Bio-Industry, Beijing, P. R.China.

**Pengxiang Zhao is the co-corresponding author, E-mail: zpx@bjut.edu.cn

*Corresponding author, Xuemei Ma, E-mail: xmma@bjut.edu.cn.

\begin{abstract}
Molecular hydrogen $\left(\mathrm{H}_{2}\right)$ exhibits a wide breadth of botanical effects especially in improving the resistance to abiotic stress. However, the primary target is not clear. Bidirectional hydrogenases have been well studied in microbes and alga, but there is a paucity of research in higher plants. Here, we used real-time spectrophotometry, gas chromatography and $\mathrm{H}_{2}$ sensor to detect the $\mathrm{H}_{2}$-evolving and $\mathrm{H}_{2}$-uptake activity of the plasma membrane (PM) vesicles of higher plants. $\mathrm{Net} \mathrm{H}^{+}, \mathrm{Na}^{+}$and $\mathrm{K}^{+}$fluxes were measured using Non-invasive Micro-test Technology (NMT). We found that the PM vesicles of Vigna radiata hypocotyls and Capsicum annuum stems have the ability of both oxidizing and producing $\mathrm{H}_{2}$. This two-way enzymatic activity coupled with the redox of ferricyanide/ferrocyanide and NADH/NAD ${ }^{+} . \mathrm{H}_{2}$ affected the $\mathrm{H}^{+}$and $\mathrm{Na}^{+}$ fluxes on the surface of $V$. radiata hypocotyls. These results demonstrate that the PM vesicles of higher plants have the abilities of $\mathrm{H}_{2}$ evolution and absorption. The bidirectional activities may act as a valve to regulate the energy balance in plant cells.
\end{abstract}

Keywords: Hydrogen evolution; Hydrogen absorption; Plasma membrane; Energy balance; Vigna radiata; Higher plants

\section{Introduction}

Molecular hydrogen $\left(\mathrm{H}_{2}\right)$ has been reported to have antioxidant-like effects by effectively protecting cells against oxidative stress [1]. Additional research has demonstrated that $\mathrm{H}_{2}$ exhibits a wide breadth of functions including anti-inflammatory, anti-allergy, anti-apoptosis, and anti-metabolic disorders[2]. In addition to the beneficial roles of $\mathrm{H}_{2}$ reported in animals, more than 30 studies have reported that it also has an important regulatory effect on the physiological function of plants. $\mathrm{H}_{2}$ could enhance the plant tolerance and resistance to several abiotic stresses such as high salinity, cadmium, paraquat exposure, heat stress, drought tolerance, as well as delaying of kiwifruit ripening[3]. $\mathrm{H}_{2}$ appears to improve redox homeostasis via modulating reactive oxygen and nitrogen species (ROS), which mediates many of the biological effects of $\mathrm{H}_{2}$ [4]. 
It's well known that microbes ranging from ancient bacteria to eukaryotic microalgae are capable of metabolism $\mathrm{H}_{2}$. Their ability to either produce or use $\mathrm{H}_{2}$ as a metabolite arises from the expression of hydrogenase enzymes [5]. Hydrogenases are the group of diverse metalloenzymes that catalyze the reversible reaction of dihydrogen into protons and electrons: $\mathrm{H}_{2}\left(\leftrightarrows \mathrm{H}^{+}+\mathrm{H}^{-}\right) \leftrightarrows 2 \mathrm{H}^{+}+2 \mathrm{e}^{-}$. The two main types of hydrogenases are classified by the metal clusters at their catalytic sites and are termed [FeFe] and [NiFe]-hydrogenases. However, only a few studies have reported $\mathrm{H}_{2}$ metabolism in higher plants.

It was hypothesized that hydrogenase enzymes exist in some higher plants in 1947 [6]. Sanadze firstly provided evidence that the leaves of higher plants could both release and absorb $\mathrm{H}_{2}$ [7]. Then Renwick's group demonstrated that many kinds of higher plants could generate $\mathrm{H}_{2}$ [8]. In 1984, Torres V. et al. reported experimental evidence for hydrogenase activity in some Gramineae palts. The germinated seeds of barley produced considerable amounts of $\mathrm{H}_{2}$ after anaerobic treatment. The $\mathrm{H}_{2}$ metabolism was due to plant tissues and not to contaminant microorganisms [9]. Subsequent studies demonstrated $\mathrm{H}_{2}$ generation from higher plants during a seed's germination or abiotic stresses in tissue lysis, e.g. barley, Arabidopsis, rice, Medicago sativa [10-13]. Zeng et al. confirmed the $\mathrm{H}_{2}$ production with the consistent $\mathrm{H}_{2}$-evolving hydrogenase activity in rice seedling lysis [14]. Compared with $\mathrm{H}_{2}$ evolution, $\mathrm{H}_{2}$ uptake in higher plants have been seldom reported. Except for chloroplasts [15], there were no other reports about the $\mathrm{H}_{2}$ metabolism sites of higher plants.

In this study, we investigated the $\mathrm{H}_{2}$-evolving and $\mathrm{H}_{2}$-uptake bidirectional activities in the plasma membrane (PM) vesicles of Vigna radiata. We demonstrate that a "hydrogenase-like complex" existed in PM acts as an electron/proton provider by oxidation of $\mathrm{H}_{2}$ or an electron acceptor by production of $\mathrm{H}_{2}$, which may help maintain the plant in redox homeostasis. Therefore, taking all the reports of physiological effects of $\mathrm{H}_{2}$ in higher plants, coupled with our novel discoveries, we propose that the variety of functions of $\mathrm{H}_{2}$ may mediated by a bidirectional $\mathrm{H}_{2}$ metabolism activity.

\section{Results}

\section{Detection of hydrogenase activities in PM vesicles of higher plants}

To investigate the $\mathrm{H}_{2}$-evolving ability of the PM vesicles in higher plants, crude PM vesicles of $V$. radiata hypocotyls were used firstly. Endogenous $\mathrm{H}_{2}$ was detected by the method of headspace GC. As shown in Figure 1A, the crude PM could release about $100 \mu \mathrm{mol} / \mathrm{L} / \mathrm{h} / \mathrm{mg}$ protein under normoxic condition and hypoxia could significantly promoted the $\mathrm{H}_{2}$ production for about $146 \mu \mathrm{mol} / \mathrm{L} / \mathrm{h} / \mathrm{mg}$ protein. Additionally, we found that metal ion chelators EDTA can completely inhibit $\mathrm{H}_{2}$ generation (Figure 1B), which indicated that the enzyme belongs to the class of metalloenzyme. Then the $\mathrm{H}_{2}$ sensor electrode was used to monitored the $\mathrm{H}_{2}$-evolving hydrogenase activity of purified PM vesicles continuously. As indicated in figure 1C, the time-course of changes in $\mathrm{H}_{2}$ levels was monitored and the maximum cumulative $\mathrm{H}_{2}$ production was $57 \mu \mathrm{mol} / \mathrm{L} / \mathrm{mg}$ protein (Figure $1 \mathrm{C}$ and Figure $\mathrm{S} 1 \mathrm{~A}$ ), but no $\mathrm{H}_{2}$ evolution was observed in boiled PM vesicles (Figure S1A). Except $V$. radiata, $\mathrm{H}_{2}$ evolution was also observed in purified PM vesicles from $C$. annuum stems and the maximum $\mathrm{H}_{2}$ production activity was about $314 \mu \mathrm{mol} / \mathrm{L} / \mathrm{mg}$ protein (Figure S1B). 
Above results indicated that the PM vesicles of higher plants were capable of producing $\mathrm{H}_{2}$ endogenously.

We further investigated whether purified PM vesicles were capable of utilizing $\mathrm{H}_{2}$ as an electron donor to reduce terminal electron acceptor. As shown in Figure 1D, the reduced BV of PM-boiled control was oxidized quickly, whereas the other groups could delay oxidation of reduced BV. The similar results were obtained in purified PM of $C$. annuum stems (Figure S2). These results indicated that $\mathrm{H}_{2}$ could be used to provide electrons to BV. Additionally, the enzymatic activity of $\mathrm{H}_{2}$-dependent BV reduction was significantly enhanced when the PM was treated with $5 \mu \mathrm{M} N A D H$ (Figure 1D and Figure S2).

\section{Other enzymatic characterization of hydrogenase activity in PM}

To further confirm this hydrogenase-like activity, we detected the $\mathrm{H}_{2}$ : $\mathrm{NAD}^{+}$redox reaction and $\mathrm{NAD}^{+}$was assayed as an electron acceptor. In our experiment, we not only observed that the PM vesicles could utilize $\mathrm{H}_{2}$ to regenerate $\mathrm{NADH}$, but also found that $\mathrm{NADH}$ was oxidized again (Figure 2A, B). Hydrogen accelerated the reversible redox reaction between $\mathrm{NAD}^{+}$and $\mathrm{NADH}$. These bidirectional redox reactions were the most evident when the PM was activated by $5 \mu \mathrm{M}$ NADH (Figure 2A) compared with non-activated PM (Figure 2B).

In this study, the activity of NADH-ferricyanide oxidoreductase (NFORase) of PM vesicles from V.radiata hypocotyls was also measured. Ferricyanide (hexacyanoferrate (III), HCF III) was used as an electron acceptor and its reduced product was HCF II, which is convenient for the investigation of electron flow[16]. The reaction of $\mathrm{HCF}$ III $+\mathrm{NADH} \rightarrow \mathrm{HCF}$ II $+\mathrm{NAD}^{+}$was detected spectrophotometrically in this experiment. The process represented $\mathrm{HCF}$ III $\rightarrow \mathrm{HCF}$ $\mathrm{II} \rightarrow \mathrm{HCF} \quad \mathrm{III} \rightarrow \mathrm{HCF} \quad$ II and $\mathrm{NADH} \rightarrow \mathrm{NAD}^{+} \rightarrow \mathrm{NADH} \rightarrow \mathrm{NAD}^{+}$conversion, which indicates a type of bidirectional redox reaction (HCF III + NADH $\leftrightarrows \mathrm{HCF}$ II $+\mathrm{NAD}^{+}$) (Figure $2 \mathrm{C}$ to $\mathrm{F}$ ). Triton $\mathrm{X}-100$ treated permeable vesicles showed a steeper decrease and increase in absorbance (Figure $2 \mathrm{E}$ and $\mathrm{F}$ ) compared with no triton treatment (Figure 2C and D). Similar to above results, the PM vesicles themselves also catalyzed the redox reaction between $\mathrm{NAD}^{+} / \mathrm{NADH}$ and $\mathrm{HCF}$ III/HCF II. $\mathrm{H}_{2}$ significantly accelerated the enzyme activity in a dose-dependent manner (i.e. 0.68 $\mathrm{mM} \mathrm{H}_{2}>0.2 \mathrm{mM} \mathrm{H}_{2}>\mathrm{H}_{2}$-free) during both the ascent and descent processes (Figure $2 \mathrm{C}$ to $\mathrm{F})$.

\section{HRW influenced the $\mathrm{H}^{+}$fluxes in $\boldsymbol{V}$. radiata}

To determine whether $\mathrm{H}_{2}$ had the influence on the growth of plants, the seeds of $V$. radiata were germinated in hydrogen-rich water (HRW) in darkness. $\mathrm{H}_{2}$ could accelerate the elongation of $V$. radiata hypocotyls significantly (Figure $3 \mathrm{~A}$ and $3 \mathrm{~B}$ ), but not its diameter (Figure 3C). The hypocotyls elongation was due to a significant extension of the cortex cells (Figure 3D). The elongation of plant cells can be promoted by $\mathrm{H}^{+}$secretion according to the acid growth hypothesis. Therefore, to confirm whether the elongation was due to the change of $\mathrm{H}^{+}$fluxes on the hypocotyls surface influenced by $\mathrm{H}_{2}$, NMT technique was used. During growth, plants rely on the roots to absorb HRW, so real-time $\mathrm{H}^{+}$fluxes of hypocotyls were measured to simulate the actual situation of using $\mathrm{H}_{2}$ while roots were treated with water which contained 
dissolved $\mathrm{H}_{2}$ or not (Figure 3E). As shown in Figure 3F and $3 \mathrm{G}$, the net $\mathrm{H}^{+}$efflux of hypocotyls was significantly enhanced by $0.8 \mathrm{mM} \mathrm{H}_{2}$.

Net $\mathrm{H}^{+}$fluxes of excised hypocotyls treated directly by $\mathrm{H}_{2}$ were also measured (Figure S3A) and there was no significant influence by either $0.2 \mathrm{mM}$ or $0.8 \mathrm{mM} \mathrm{H}_{2}$ (Figure S3B and S3C). This discrepancy compared with the intact seedlings might due to the tissues condition and the way of $\mathrm{H}_{2}$ treatment. The excised hypocotyls were surrounded by $\mathrm{H}_{2}$ and $\mathrm{H}_{2}$ could be used by both surface and inner of hypocotyls. If the concentrations of $\mathrm{H}^{+}$inside and outside the hypocotyls changed at the same time, the change of $\mathrm{H}^{+}$flow probably could not be observed.

To further investigate the $\mathrm{H}_{2}$ influence when plants faced abiotic stress, the $\mathrm{H}^{+}, \mathrm{Na}^{+}$, and $\mathrm{K}^{+}$fluxes of hypocotyls under salt stress were detected. As shown in Figure $3 \mathrm{H}$ and 3I, $\mathrm{H}_{2}$ promoted $\mathrm{H}^{+}$effluxes that were similar with the above results. Except for changes in $\mathrm{H}^{+}$effluxes, $\mathrm{H}_{2}$ also significantly reduced $\mathrm{Na}^{+}$influx (Figure $3 \mathrm{~J}$ and $3 \mathrm{~K}$ ), but had no influences on $\mathrm{K}^{+}$flux (Figure $3 \mathrm{~L}$ and $3 \mathrm{M}$ ). We suggested that the transport of salt ions across the membrane could be affected by the $\mathrm{H}_{2}$-uptake activitiy in PM vesicles, which could split $\mathrm{H}_{2}$ into protons.

\section{Discussion}

It has been shown that exogenous $\mathrm{H}_{2}$ has positive botanical effects on plant growth and abiotic stress adaptability but with limited knowledge about its primary targets[3]. The PM plays an important role in plant responses to the environment in order to survive stresses since almost all environmental changes are initially perceived by the PM [17]. The investigation of $\mathrm{H}_{2}$ metobolism in PM vesicles could help to provide insights into the underlying molecular mechanisms responsible for the extensive biological effects of $\mathrm{H}_{2}$ on higher plants.

\section{$\mathrm{H}_{2}$-evolving and $\mathrm{H}_{2}$-uptake activities existed in $\mathrm{PM}$ vesicles of higher plants}

All the catalytic properties detected in our study demonstrate that the PM vesicles contain reversible and functional $\mathrm{H}_{2}$ metabolism activities. The classical methods in detecting $\mathrm{H}_{2}$ uptake and $\mathrm{H}_{2}$ evolution by hydrogenase enzymes were used. $\mathrm{H}_{2}$ could be oxidized directly to provide electrons to $\mathrm{BV}, \mathrm{NAD}^{+}$or $\mathrm{HCF}$ (III) (Figure $1 \mathrm{D}$ and Figure 2). The enzymatic activity of $\mathrm{H}_{2}$-dependent $\mathrm{BV}$ reduction was significantly enhanced by $5 \mu \mathrm{M}$ NADH (Figure 1D, Figure S2). This property was consistent with hydrogenase, which can be activated by small amounts of NADH [18]. Conversely, protons could be reduced to $\mathrm{H}_{2}$ by accepting electrons from reduced MV (Figure 1C, Figure S1). Previous studies $[18,19]$ have shown that $\mathrm{NAD}^{+}$-reducing hydrogenase has the module-specific enzymatic activities, e.g., the oxidation of $\mathrm{NAD}(\mathrm{P}) \mathrm{H}$ with ferricyanide as electron acceptor. In our study, the NFORase activities were found in PM vesicles of $V$. radiata and primary active sites maybe located on the cytoplasmic side of PM, which is consistent with previous studies [20]. Importantly, our study reports the bi-directional circulation of $\mathrm{NAD}^{+} \leftrightarrow \mathrm{NADH}$ and $\mathrm{HCF}$ (III) $\leftrightarrow \mathrm{HCF}$ (II), and $\mathrm{H}_{2}$ could accelerate both of these redox reactions (Figure 2). These results suggest that the module-specific enzymatic activities of $\mathrm{NAD}^{+}$-reducing hydrogenase also existed in $\mathrm{PM}$ vesicles and $\mathrm{H}_{2}$ participates in the bidirectional redox.

The redox state of cells, especially the level and ratio of $\mathrm{NAD}^{+} / \mathrm{NADH}$, directly affects the vital processes of organism growth, aging, and death. The hydrogenase-like activities in PM vesicles is likely involved in the cellular NAD $(H)$ 
pool. The hydrogenase of Ralstonia eutropha could couple $\mathrm{H}_{2}$ oxidation with the reduction of $\mathrm{NAD}^{+}$to $\mathrm{NADH}$, conversely it also catalyzes the formation of $\mathrm{H}_{2}$ from $\mathrm{NADH}$ to prevent 'over-reduction' of the cytoplasm under $\mathrm{O}_{2}$-limiting conditions [21]. It is conceivable that the "valve" effect of bidirectional activities of $\mathrm{H}_{2}$-oxidation and $\mathrm{H}_{2}$-evolution plays an important role in regulating the energy homeostasis of plants. Researchers have found that some abiotic stresses increase endogenous $\mathrm{H}_{2}$ production in higher plants, and $\mathrm{H}_{2}$ could alleviate damage induced by abiotic stresses $[12,13]$. $\mathrm{Wu}$ et al. reported that $\mathrm{H}_{2}$ alleviated $\mathrm{Cd}$ stress through ROS detoxification by reestablishing glutathione homeostasis [22]. Chen found that HRW pretreatment remarkably attenuated heat stress-induced lipid peroxidation and antioxidant dysregulation in cucumber leaves [23]. Many botanical effects of $\mathrm{H}_{2}$ in plants are at least partially related to the reestablishment of redox homeostasis under abiotic stress. We speculate that the primary mechanism of how $\mathrm{H}_{2}$ promotes plant resistance is due to the functional activity of bidirectional $\mathrm{H}_{2}$-oxidation and $\mathrm{H}_{2}$-evolution. When energy (electron density) is high, $\mathrm{H}_{2}$ may be produced, which may also regulate reactive oxygen species (ROS). On the other hand, when energy is low, $\mathrm{H}_{2}$ can be activated by the hydrogenase to produce energy.

\section{$\mathrm{H}_{2}$ metabolism of PM can influence the transmembrane ion flow}

Hydrogenases are involved in membrane-linked energy conservation and ion transportation through the generation of a transmembrane proton force [24]. In higher plants, membrane electrochemical potential gradient is closely related with a variety of biological functions such as ion transport, signal transduction, nutrient uptake, cell elongation, cellular $\mathrm{pH}$ regulation, etc. [25]. On the basis of homology modules between hydrogenases and complex I of the respiratory chain, hydrogenases are proposed to work as an ion $\left(\mathrm{H}^{+}\right.$or $\left.\mathrm{Na}^{+}\right)$pump [26, 27]. The mechanism of energy conservation by $\mathrm{Na}^{+} / \mathrm{H}^{+}$translocation has been best studied with $[\mathrm{NiFe}]$ hydrogenases from methanogens $[28,29]$.

In our research, we designed a simple but very practical method to measure net ion fluxes of hypocotyls where the roots were subjected to different treatments simultaneously (Figure 3E). We found that $\mathrm{H}_{2}$ could promoted the formation of proton-motive force across the membrane. The effects of $\mathrm{H}_{2}$ on ion fluxes that probably due to $\mathrm{H}_{2}$-uptake activities (i.e. $\mathrm{H}_{2} \rightarrow 2 \mathrm{H}^{+}+2 \mathrm{e}^{-}$). The electrochemical gradient can be converted into chemical energy for storage under the appropriate conditions. According to the acid growth hypothesis, elongation of plant cells can be promoted by $\mathrm{H}^{+}$secretion and rapid acidification of the extension-limiting cell wall [30]. Therefore, the $\mathrm{H}_{2}$-uptaking activity of $\mathrm{PM}$ vesicles in $V$. radiata may provide a possible explanation for how $\mathrm{H}_{2}$ promotes hypocotyls elongation.

In addition to the effects on plant development, $\mathrm{H}_{2}$ also plays an important role in plant resistance to abiotic stress, such as salt tolerance [11]. The discovery of reducing $\mathrm{Na}^{+}$influx (Figure 3J, 3K), may partly account for why $\mathrm{H}_{2}$ treatment attenuates salinity-induced growth inhibition in Arabidopsis [11].

\section{Hypothetical schematic diagrams of $\mathrm{H}_{2}$ metabolism in higher plants PM}

According to our present knowledge, we propose a schematic diagram of $\mathrm{H}_{2}$ metabolism ( $\mathrm{H}_{2}$-evolving and $\mathrm{H}_{2}$-uptaking) in $\mathrm{PM}$ vesicles of higher plants (Figure 4). Hydrogen acts directly as a proton and an electron donor. The flow of electrons and 
protons in carrying energy is the basis of all biosynthesis in life, which is inseparable from the coupling of oxidation and reduction reactions. The "valve" effect of bidirectional hydrogenases can play a very important role in regulating the energy homeostasis of plants. The discoveries in this study may provide some new insights about the molecular mechanisms of $\mathrm{H}_{2}$ and how to interpret its broad biological effects. The PM hydrogenase protein and its functions should be identified and analyzed in the future.

\section{Materials and methods}

Preparation of hydrogen-rich solutions. Purified $\mathrm{H}_{2}(99.999 \%)$ was generated by ZK200-hydrogen-producing apparatus from Zhongke Huiheng technology development Co. Ltd. (Beijing, China), then bubbled into $\mathrm{ddH}_{2} \mathrm{O}$ or required solution at a rate of $220 \mathrm{~mL} \mathrm{~min}^{-1}$ in $0.1 \mathrm{MPa}$ for at least $20 \mathrm{~min}$ until $\mathrm{H}_{2}$ concentration reached saturation. Afterwards, the $\mathrm{H}_{2}$-saturated solution $(0.8 \mathrm{mM})$ was immediately diluted to $0.2 \mathrm{mM}, 0.4 \mathrm{mM}$ or $0.68 \mathrm{mM}$. All $\mathrm{H}_{2}$-rich solution was freshly prepared. The $\mathrm{H}_{2}$ dissolved in solution was measured using a needle-type $\mathrm{H}_{2}$ sensor (Unisense, Aarhus N, Denmark).

Plant materials. Mung beans (Vigna radiata [L.] R. Wilczek) were soaked in sterile $\mathrm{ddH}_{2} \mathrm{O}$ for 8 hours and grew in $\mathrm{ddH}_{2} \mathrm{O}$ at $23 \pm 1^{\circ} \mathrm{C}$ in darkness. Hypocotyls of 60-hour-old $V$. radiata were harvested for PM preparation. Intact plants or 5-mm long segments of hypocotyls (cut $5 \mathrm{~mm}$ below the cotyledons) were used for ion flux measurements. C. annuum were purchased from Shouguang Hongxiang Horticulture Co., Ltd. Stems of 4-week-old seedlings of $C$. annuum were harvested for PM preparation. To investigate the effects of hydrogen-rich water (HRW) on growth of $V$. radiata, the seeds of $V$. radiata were cultured in HRW containing $0.8 \mathrm{mM} \mathrm{H}_{2}$ for 3 days and continued to culture in $\mathrm{H}_{2}$-free water for another 2 days. Seedlings cultured in $\mathrm{H}_{2}$-free water were regarded as the negative control. Finally, the length and diameter of hypocotyls were measured. Assays were repeated with at least three independent experiments.

Preparation of plasma membrane. The PM vesicles from $V$. radiata and $C$. annuum were prepared and purified as described previously with minor modifications-[31]. The crude PM vesicles were dissolved in the suspended buffer containing $5 \mathrm{mM}$ potassium phosphate buffer ( $\mathrm{pH} 7.8$ ), $5 \mathrm{mM} \mathrm{KCl,} 0.25 \mathrm{M}$ sucrose, $0.5 \% \mathrm{BSA}(\mathrm{W} / \mathrm{V}$ ) and $1 \mathrm{mM}$ DTT. The PM vesicles were purified from microsomal fractions by partitioning in an aqueous polymer two-phase system. The ratio of hypocotyls weight to two-phase weight is 32: 8. The final pellet was re-suspended in the suspended buffer containing $10 \%(\mathrm{~W} / \mathrm{V})$ mannitol, put into liquid nitrogen immediately and stored at $-80^{\circ} \mathrm{C}$ until used. All the operations of extraction processes were performed at $4^{\circ} \mathrm{C}$. Protein concentration was measured using Bradford protein assay kit (Tiangen Biotech, Beijing Co., LTD, CN). The purity of the PM was determined by standard marker assays[32]. Table S1 illustrated that the PM purity was enough to be used for further assay.

Measurement of $\mathbf{H}_{2}$ production of the PM. $\mathrm{H}_{2}$ evolution of crude $\mathrm{PM}$ was monitored by headspace gas chromatography (GC) (Shimadzu, GCMS-QP2010S). A total volume of $500 \mu \mathrm{L}$ reaction mixture in $1.9 \mathrm{~mL}$ gas chromatographic flasks containing about $2 \mathrm{mg}$ crude PM and suspended buffer. The hypoxia conditions were obtained by flushing with nitrogen $\left(\mathrm{N}_{2}\right)$ into the headspace of $\mathrm{GC}$ flasks for 2 minutes 
to remove $\mathrm{O}_{2}$. To study the effects of EDTA on $\mathrm{H}_{2}$ production, the reaction mixture was added with or without $1 \mathrm{mM}$ EDTA-Na $\mathrm{Na}_{2}$.

$\mathrm{H}_{2}$ produced by purify $\mathrm{PM}$ and dissolved in reaction solution was detected continually with a needle-type $\mathrm{H}_{2}$ sensor. $\mathrm{H}_{2}$ evolution was monitored in a total volume of $200 \mu \mathrm{L}$ reaction mixtures. Potassium phosphate buffer $(100 \mathrm{mM}, \mathrm{pH} 7.0)$ containing $2.5 \mathrm{mM}$ MV was first bubbled with $\mathrm{N}_{2}$ to remove the $\mathrm{O}_{2}$, and then $80 \mu \mathrm{g}$ purified PM vesicles (PM pretreated with $0.05 \%$ tritonX-100 and $5 \mu \mathrm{g}$ NADH) were added. The reaction was initiated by addition of $10 \mathrm{mM} \mathrm{Na}_{2} \mathrm{~S}_{2} \mathrm{O}_{4}$, which was freshly prepared with oxygen removed by sparging with $\mathrm{N}_{2}$. The PM vesicles boiled for 10 min served as the negative control.

$\mathrm{H}_{2}$-dependent BV (benzyl viologen) reduction. $\mathrm{H}_{2}$ uptake hydrogenase activity $\left(\mathrm{H}_{2}\right.$-dependent reduction of $\left.\mathrm{BV}\right)$ was assayed spectrophotometrically at room temperature according to Pinske $\mathrm{C}$ at $578 \mathrm{~nm}$ [33] except that the buffer was $100 \mathrm{mM}$ potassium phosphate $(\mathrm{pH} 7.0) . \mathrm{H}_{2}$ oxidation was recorded by the absorbance change of reduced BV. The final volume of $100 \mu \mathrm{L}$ reaction mixture including $100 \mathrm{mM}$ $\mathrm{H}_{2}$-saturated potassium phosphate $(\mathrm{pH} 7.0), 4 \mathrm{mM}$ oxidized $\mathrm{BV}$, and 10-20 $\mu \mathrm{g} \mathrm{PM}$ (pre-treated with $0.05 \%$ tritonX-100 for 10 minutes on ice). Before reaction, either 5 $\mu \mathrm{M}$ NADH was added (to activate the PM), or nothing was added. The reaction was started by adding of $0.5 \mathrm{mM}$ sodium dithionite $\left(\mathrm{Na}_{2} \mathrm{~S}_{2} \mathrm{O}_{4}\right)$. The PM vesicles that were boiled for 10 minutes served as the negative control. Assays were repeated with three independent experiments.

NFORase enzymatic assay. NADH-ferricyanide oxidoreductase (NFORase) activity was tested at room temperature in the absence or presence of $0.2 \mathrm{mM}$ or $0.68 \mathrm{mM} \mathrm{H}_{2}$. The activity was monitored by microplate readerVICTOR ${ }^{3}$ (Perkin Elmer Life Sciences, Waltham, MA, USA) as the time-dependent A420 and A340 absorbance change of ferricyanide $\left(\varepsilon 420=1.0 \mathrm{mM}^{-1} \cdot \mathrm{cm}^{-1}\right)$ and NADH $\left(\varepsilon 340=6.22 \mathrm{mM}^{-1} \cdot \mathrm{cm}^{-1}\right)$, respectively. Firstly, the reaction mixture containing $1.5 \mathrm{mM} \mathrm{K}_{3}\left[\mathrm{Fe}(\mathrm{CN})_{6}\right]$ and reaction buffer $(10 \mathrm{mM} \mathrm{KCl}, 3 \mathrm{mM} \mathrm{MgSO} 4,50 \mathrm{mM}$ Tris- $\mathrm{HCl}, \mathrm{pH} 7.5)$ were added into 96-well plates to detect absorbance. After approximately 5 minutes of measurement, the reaction mixture was added by premixed $0.2 \mathrm{mM} \mathrm{NADH}$ and 10-20 $\mu \mathrm{g}$ PM vesicles (pre-treated with or without $0.05 \%$ tritonX-100 on ice for 10 minutes) in the final volume of $100 \mu \mathrm{L}$. The group without the addition of PM was used as blank control. The NFORase activity was recorded over approximately a 45-min time course. Detailed conditions of assay are provided in the legends of the figures. Data are presented as standard deviation of the mean. Results of activity measurements were repeated twice in independent experiments.

NADH regeneration. $\mathrm{H}_{2}$-driven reduction of $\mathrm{NAD}^{+}$to $\mathrm{NADH}$ was detected spectrophotometrically at $340 \mathrm{~nm}$ [34]. NADH regeneration was monitored in a total volume of $100 \mu \mathrm{L}$ of $\mathrm{H}_{2}$-saturated Tris- $\mathrm{HCl}$ buffer $(50 \mathrm{mM}, \mathrm{pH} 8.0)$ containing 0.4 $\mathrm{mM} \mathrm{NAD}{ }^{+}$. Before adding to the reaction mixture, the PM vesicles of $V$. radiata hypocotyls were pre-treated with $0.05 \%$ tritonX-100 for 10 minutes on ice and activated by $5 \mu \mathrm{M}$ NADH [18]. The reaction was started by adding 10-20 $\mu \mathrm{g}$ PM. PM was not added in the blank control. Results of activity measurements presented in this paper were repeated twice in independent experiments.

Measurement of net ion flux with the NMT system. Net ion fluxes were measured noninvasively using Non-invasive Micro-test Technology (NMT; NMT100-SIM-YG, 
Younger USA LLC, Amherst, MA01002, USA). The gradients of ion concentration were measured by moving the ion-selective microelectrode between two positions close to the hypocotyl surface of approximately $8 \mathrm{~mm}$ below the cotyledons in a preset excursion $(20 \mu \mathrm{m}$ and $50 \mu \mathrm{m}$ from the hypocotyl surface, along an axis perpendicular to the hypocotyls). Sixty-hour old $V$. radiata plant's seedlings or excised hypocotyls were equilibrated in measuring solution $(0.1 \mathrm{mM} \mathrm{KCl}, 0.1 \mathrm{mM}$ $\mathrm{CaCl}_{2}, 0.1 \mathrm{mM} \mathrm{MgSO}$, $0.1 \mathrm{mM} \mathrm{NaCl}, 0.3 \mathrm{mM}$ MES, pH 6.0) for 10 min. Intact plants were placed in the $90 \mathrm{~mm}$ three-compartment plastic petri dishes. The hypocotyls and roots were placed in separate cells. A small notch was made in the barrier, which was between two cells to hold the seedlings (Figure 3E). The hypocotyls were soaked in fresh measuring solution and roots of intact plants were immersed in $\mathrm{H}_{2}$-free $\mathrm{ddH}_{2} \mathrm{O}$ or $\mathrm{H}_{2}$-free $150 \mathrm{mM} \mathrm{NaCl}$ solution. Stable net fluxes of $\mathrm{H}^{+}$, $\mathrm{Na}^{+}$, or $\mathrm{K}^{+}$ions were measured for approximately 5 minutes. The $\mathrm{H}_{2}$-free $\mathrm{ddH}_{2} \mathrm{O}$ or $\mathrm{NaCl}$ was then replaced by $\mathrm{ddH}_{2} \mathrm{O}$ containing $0.8 \mathrm{mM} \mathrm{H}_{2}$ or $\mathrm{NaCl}$ containing $0.8 \mathrm{mM}$ $\mathrm{H}_{2}$, respectively. The $\mathrm{H}_{2}$-free measuring solution impregnated with the excised hypocotyls was replaced by solution containing $0.2 \mathrm{mM} \mathrm{H}_{2}$ or $0.8 \mathrm{mM} \mathrm{H}_{2}$. The net ion fluxes on the hypocotyls were measured for approximately another 5 minutes. Five to seven repetitions were carried out for the ion fluxes detection. All measurements of ion fluxes were carried out at Xuyue (Beijing) Sci. \& Tech. Co., Ltd. (Beijing, China).

Statistical Analysis. Unpaired t-test (two-tailed) was used to compare data from two groups. Data are expressed as mean $\pm \mathrm{SD}$. Differences with P-values $<0.05$ were considered significant. GraphPad Prism 6.0 was used for data analysis and figure creation.

\section{Compliance and ethics}

The authors declare that they have no conflicts of interest with the contents of this article.

\section{Acknowledgments}

We thank Fei Guo of the Institute of Pathogen Biology, Chinese Academy of Medical Sciences \& Peking Union Medical College Research Center, for generous equipment support of PM extraction, and Jian Li, a member of their laboratory for helpful assistance. This work was supported by Special Fund for Agro-scientific Research in the Public Interest (201303023), Beijing Postdoctoral Research Foundation (2017-ZZ-019), Chaoyang District Postdoctoral Research Foundation (2018ZZ-01-11) and National Natural Science Foundation of China (81602408).

\section{References}

[1] I. Ohsawa, M. Ishikawa, K. Takahashi, M. Watanabe, K. Nishimaki, K. Yamagata, K. Katsura, Y.

Katayama, S. Asoh, S. Ohta, Hydrogen acts as a therapeutic antioxidant by selectively reducing cytotoxic oxygen radicals, Nature Medicine, 13 (2007) 688-694.

[2] L. Huang, Molecular hydrogen: a therapeutic antioxidant and beyond, Medical Gas Research, 6 (2016) 219-222.

[3] J. Zeng, Z. Ye, X. Sun, Progress in the study of biological effects of hydrogen on higher plants and its promising application in agriculture, Medical Gas Research, 4 (2014) 15. 
[4] Y. Xie, Y. Mao, W. Zhang, D. Lai, Q. Wang, W. Shen, Reactive Oxygen Species-Dependent Nitric Oxide Production Contributes to Hydrogen-Promoted Stomatal Closure in Arabidopsis, Plant physiology, 165 (2014) 759-773.

[5] L. Wolfgang, O. Hideaki, R. Olaf, R. Edward, Hydrogenases, Chemical Reviews, 114 (2014) 4081-4148.

[6] E. Boichenko, Hydrogenase from isolated chloroplasts, Biokhimiya, (1947) 153-162.

[7] G.A. Sanadze, Absorption of molecular hydrogen by green leaves in light, Fiziologiya Rastenii, 8 (1961) 555-559.

[8] G.M. Renwick, C. Giumarro, S.M. Siegel, Hydrogen Metabolism in Higher Plants, Plant physiology, 39 (1964) 303-306.

[9] V. Torres, A. Ballesteros, V.M. Fernández, M. Núñez, Expression of Hydrogenase Activity in Cereals, Annals of the New York Academy of Sciences, 434 (1984) 296-298.

[10] V. Torres, A. Ballesteros, V.M. Fernández, Expression of hydrogenase activity in barley ( Hordeum vulgare L.) after anaerobic stress, Archives of Biochemistry \& Biophysics, 245 (1986) 174-178.

[11] Y. Xie, Y. Mao, D. Lai, W. Zhang, W. Shen, $\mathrm{H}_{2}$ enhances arabidopsis salt tolerance by manipulating zat10/12-mediated antioxidant defence and controlling sodium exclusion, Plos One, 7 (2012) e49800.

[12] S. Xu, S. Zhu, Y. Jiang, N. Wang, R. Wang, W. Shen, J. Yang, Hydrogen-rich water alleviates salt stress in rice during seed germination, Plant and Soil, 370 (2013) 47-57.

[13] Y. Xie, W. Zhang, X. Duan, C. Dai, Y. Zhang, W. Cui, R. Wang, W. Shen, Hydrogen-rich water-alleviated ultraviolet-B-triggered oxidative damage is partially associated with the manipulation of the metabolism of (iso)flavonoids and antioxidant defence in Medicago sativa, Functional Plant Biology, 42 (2015) 1-10.

[14] J. Zeng, M. Zhang, X. Sun, Molecular hydrogen is involved in phytohormone signaling and stress responses in plants, PloS one, 8 (2013) e71038.

[15] S.V. Mal'tsev, S.I. Allakhverdiev, V.V. Klimov, A.A. Krasnovsky, Hydrogen evolution by subchloroplast preparations of photosystem II from pea and spinach, FEBS Lett, 240 (1988) 1-5.

[16] C. Picco, J. Scholz-Starke, M. Festa, A. Costa, F. Sparla, P. Trost, A. Carpaneto, Direct Recording of Trans-Plasma Membrane Electron Currents Mediated by a Member of the Cytochrome b561 Family of Soybean, Plant Physiology, 169 (2015) 986.

[17] A.L.B. Møller, K. Witzel, A. Vertommen, V. Barkholt, B. Svensson, S. Carpentier, H.P. Mock, C. Finnie, Plant Plasma Membrane Proteomics: Challenges and Possibilities, Springer Netherlands2011.

[18] T. Burgdorf, d.L.E. Van, M. Bernhard, Q.Y. Yin, J.W. Back, A.F. Hartog, A.O. Muijsers, C.G. de Koster, S.P. Albracht, B. Friedrich, The soluble NAD+-Reducing [NiFe]-hydrogenase from Ralstonia eutropha H16 consists of six subunits and can be specifically activated by NADPH, Journal of Bacteriology, 187 (2005) 3122.

[19] M. Horch, L. Lauterbach, O. Lenz, P. Hildebrandt, I. Zebger, NAD(H)-coupled hydrogen cycling structure-function relationships of bidirectional [NiFe] hydrogenases, Febs Letters, 586 (2012) $545-556$

[20] A. Bérczi, A.O. Brightman, NADH-ferricyanide oxidoreductase is present on both sides of plant plasma membrane, Plant Science, 97 (1994) 47-52. 
[21] V. Tejwani, F.J. Schmitt, S. Wilkening, I. Zebger, M. Horch, O. Lenz, T. Friedrich, Investigation of the NADH/NAD + ratio in Ralstonia eutropha using the fluorescence reporter protein Peredox, Biochim Biophys Acta., 1858 (2017) 86-94.

[22] Q. Wu, N. Su, Q. Chen, W. Shen, Z. Shen, Y. Xia, J. Cui, Cadmium-Induced Hydrogen Accumulation Is Involved in Cadmium Tolerance inBrassica campestrisby Reestablishment of Reduced Glutathione Homeostasis, Plos One, 10 (2015) e0139956.

[23] Q. Chen, X. Zhao, D. Lei, S. Hu, Z. Shen, W. Shen, X. Xu, Hydrogen-rich water pretreatment alters photosynthetic gas exchange, chlorophyll fluorescence, and antioxidant activities in heat-stressed cucumber leaves, Plant Growth Regulation, (2017) 1-14.

[24] P.M. Vignais, B. Billoud, Occurrence, classification, and biological function of hydrogenases: an overview, Chemical Reviews, 38 (2007) 4206-4272.

[25] G. Duby, M. Boutry, The plant plasma membrane proton pump ATPase: a highly regulated P-type ATPase with multiple physiological roles, Pflugers Archiv European Journal of Physiology, 457 (2009) 645.

[26] P.M. Vignais, Hydrogenases and $\mathrm{H}(+)$-reduction in primary energy conservation, Results \& Problems in Cell Differentiation, 45 (2008) 223-252.

[27] U. Deppenmeier, The Membrane-Bound Electron Transport System of Methanosarcina Species, Journal of Bioenergetics and Biomembranes, 36 (2004) 55-64.

[28] R. Hedderich, L. Forzi, Energy-converting [NiFe] hydrogenases: more than just $\mathrm{H}_{2}$ activation, Journal of molecular microbiology and biotechnology, 10 (2005) 92-104.

[29] R. Hedderich, Energy-Converting [NiFe] Hydrogenases from Archaea and Extremophiles: Ancestors of Complex I, Journal of Bioenergetics and Biomembranes, 36 (2004) 65-75.

[30] H. Luthen, M. Bigdon, M. Bottger, Reexamination of the Acid growth theory of auxin action, Plant Physiol, 93 (1990) 931-939.

[31] B. Wen, J. Bin, R. Pan, X. Wang, Isolation of mung bean plasma membrane vesicles and the analyses of hydrolysis activity of PM H+-ATPase, Chinese Bulletin of Botany, 21 (2004) 319-325.

[32] M. Burzyński, E. Kolano, In vivoandin vitroeffects of copper and cadmium on the plasma membrane H+-ATPase from cucumber (Cucumis sativusL.) and maize (Zea maysL.) roots, Acta Physiologiae Plantarum, 25 39-45.

[33] C. Pinske, S. Krüger, B. Soboh, C. Ihling, M. Kuhns, M. Braussemann, M. Jaroschinsky, C. Sauer, F. Sargent, A. Sinz, Efficient electron transfer from hydrogen to benzyl viologen by the [NiFe]-hydrogenases of Escherichia coli is dependent on the coexpression of the iron-sulfur cluster-containing small subunit, Archives of Microbiology, 193 (2011) 893-903.

[34] B. Payen, M. Segui, P. Monsan, K. Schneider, C.G. Friedrich, H.G. Schlegel, Use of cytoplasmic hydrogenase from alcaligenes eutrophus for NADH regeneration, Biotechnology Letters, 5 (1983) 463-468. 

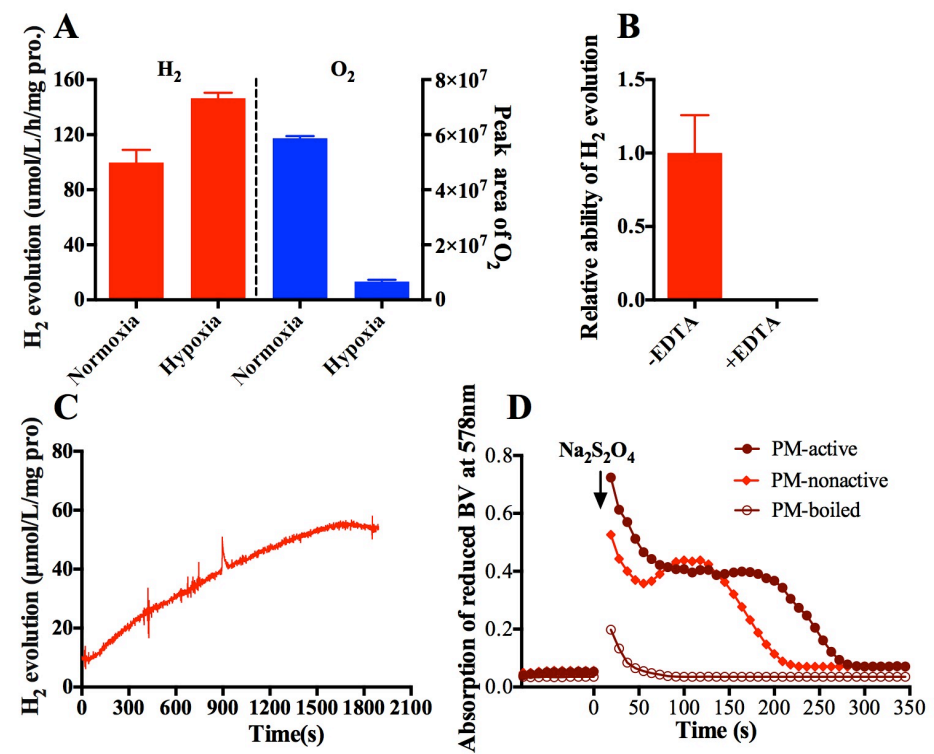

Figure 1 The bidirectional hydrogenase activities of PM vesicles from Vradiata hypocotyls. (A) The effect of $\mathrm{O}_{2}$ on $\mathrm{H}_{2}$ evolution of crude PM vesicles. (B) The effect of EDTA on $\mathrm{H}_{2}$ evolution of crude PM vesicles. (C) The $\mathrm{H}_{2}$ evolution activity of purified $\mathrm{PM}$ detected by $\mathrm{H}_{2}$-sensor. (D) The time-course of $\mathrm{H}_{2}$ uptake activities of purified PM vesicles. PM vesicles were either active or non-active with or without $5 \mu \mathrm{M}$ NADH. $\mathrm{Na}_{2} \mathrm{~S}_{2} \mathrm{O}_{4}$ initiated the reactions as indicated by arrows. 
A

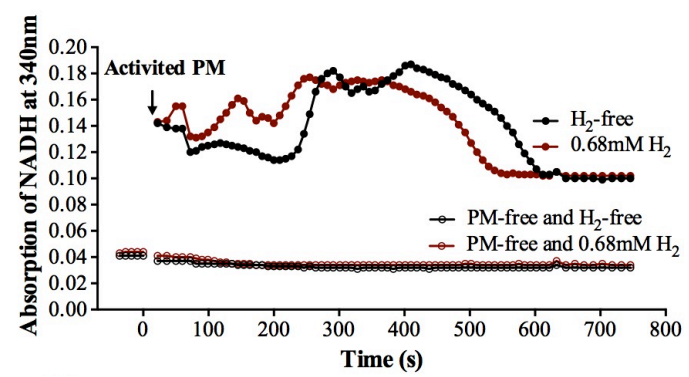

\section{C}

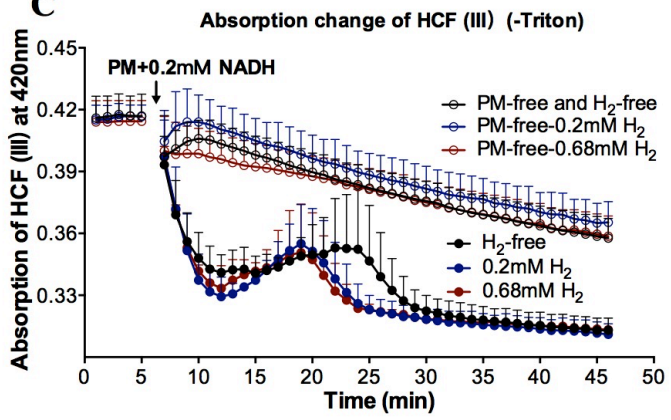

$\mathbf{E}$

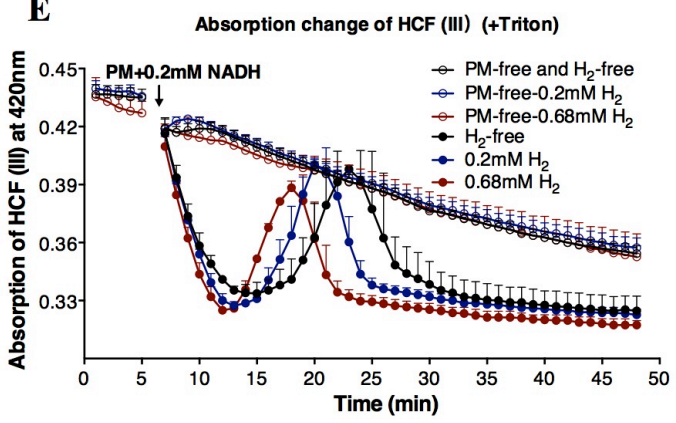

\section{B}

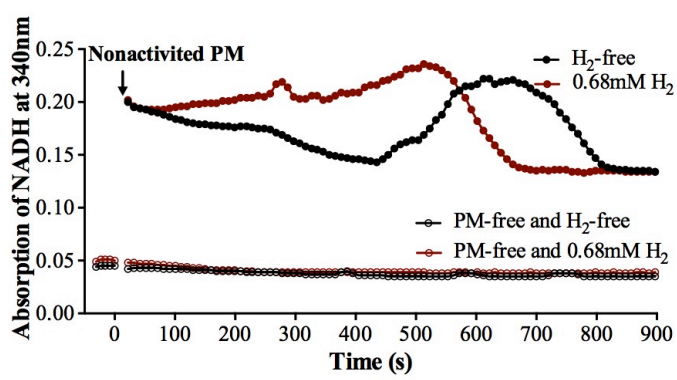

D
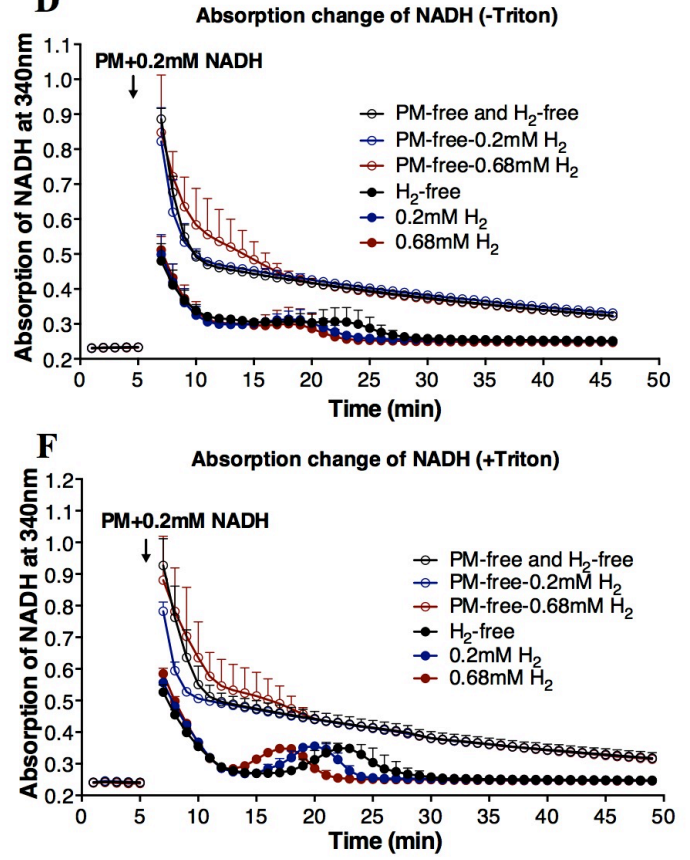

Figure 2 Other subunits redox activities of hydrogenase were measured by time-course spectrophotometric methods. (A, B) Time-course of absorption change detected for NADH $(340 \mathrm{~nm})$ in V.radiata. The PM vesicles were activated by $5 \mu \mathrm{M}$ NADH (A) or not (B). The reaction was initiated by addition of 10-20 $\mu \mathrm{g}$ PM. (C to F) Time-course of absorption change detected for HCF III (420 nm) and NADH $(340 \mathrm{~nm}$ ) simultaneously by the addition of 10-20 $\mu \mathrm{g}$ PM and $0.2 \mathrm{mM} \mathrm{NADH}$ as indicated by arrows. PM was pretreated in the absence $(\mathbf{C}, \mathbf{D})$ or presence $(\mathbf{E}, \mathbf{F})$ of $0.05 \%$ triton X-100 for 10 min to change the permeability of PM vesicles. Data shown are the means \pm SD $(n=3)$. PM-free, without $\mathrm{PM} . \mathrm{H}_{2}$-free, $\mathrm{PM}$ was added into reaction buffer without $\mathrm{H}_{2}$. Black color represents that the reaction buffer did not contain $\mathrm{H}_{2}$. Blue and red colors represent that the reaction buffer contained 0.2 $\mathrm{mM}$ or $0.68 \mathrm{mM} \mathrm{H}_{2}$. 
A
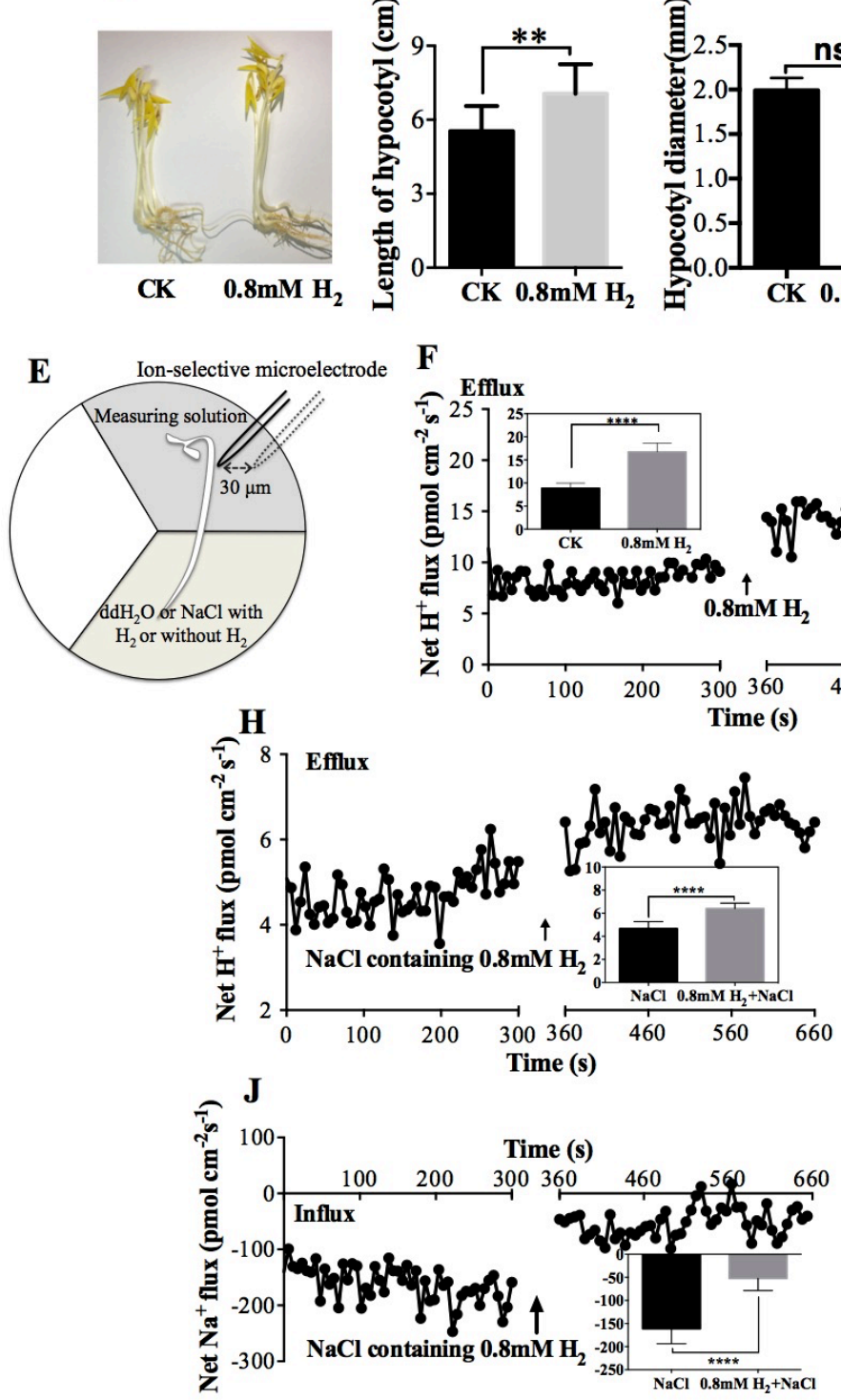

$\mathbf{L}$

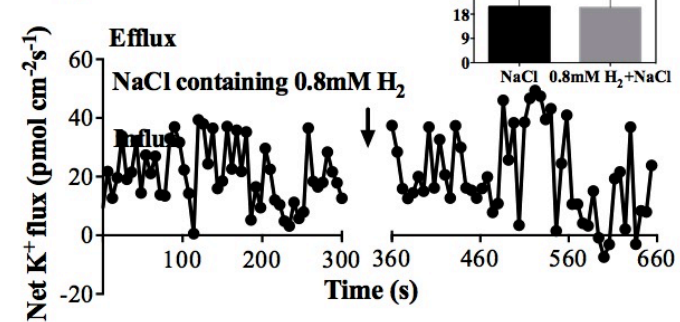

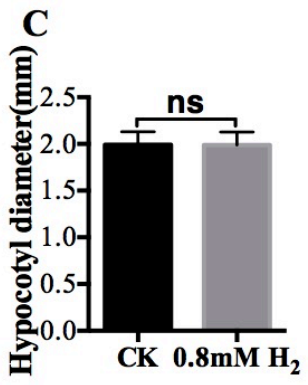

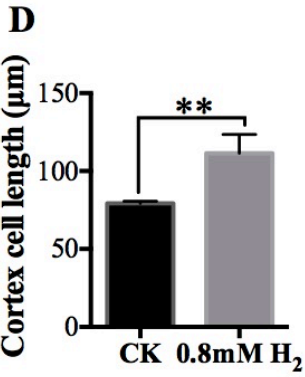

G

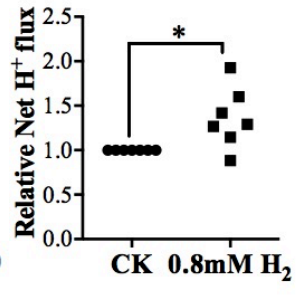

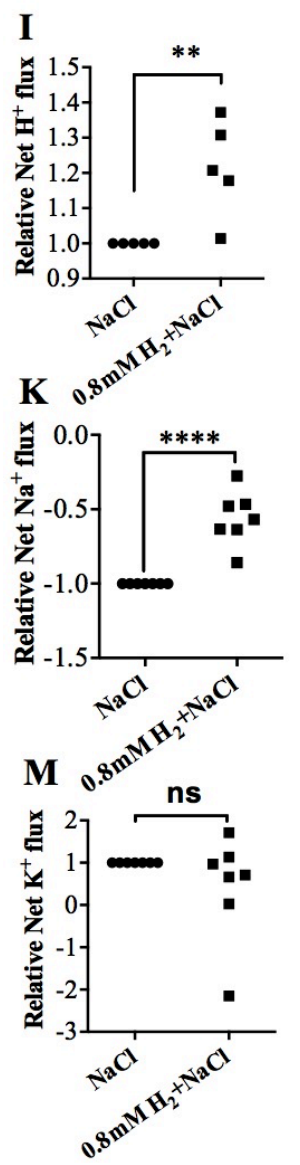

Figure 3 Biological effects of $\mathrm{H}_{2}$ on $V$. radiata. (A-D) Hydrogen's biological effects on the growth of seedlings (A), the length of hypocotyls (mean $\pm \mathrm{SD}, \mathrm{n}=12$ ) (B), the diameter of hypocotyls (mean $\pm \mathrm{SD}$, $\mathrm{n}=15$ ) (C) and the cortex cell length of hypocotyls (mean $\pm \mathrm{SD}, \mathrm{n}=4$ ) (D). $\mathrm{CK}, \mathrm{H}_{2}$-free water. (E) Schematic diagram of net $\mathrm{H}^{+}$-fluxes measurement of hypocotyls from intact $V$. radiata seedlings by NMT. (F) Net $\mathrm{H}^{+}$fluxes of the hypocotyls influenced by $0.8 \mathrm{mM} \mathrm{H}_{2}$. The net $\mathrm{H}^{+}$fluxes from a representative sample are shown. Steady ion fluxes without $\mathrm{H}_{2}$ treatment were examined for $5 \mathrm{~min}$, after which the treatment solution of roots was replaced by HRW as indicated by arrows. The mean ion 
fluxes within the measuring periods of treatment with or without $\mathrm{H}_{2}$ are shown in illustrations. (G) Relative net ion fluxes of 7 samples are shown. (H, $\mathbf{J}$ and $\mathbf{L}) 0.8 \mathrm{mM} \mathrm{H}_{2}$ effects on net $\mathrm{H}^{+}(\mathbf{H}), \mathrm{Na}^{+}(\mathbf{J})$ or $\mathrm{K}^{+}$(L) fluxes of the hypocotyls under $150 \mathrm{mM} \mathrm{NaCl}$ were detected. The net ion fluxes from a representative sample are shown. Steady ion fluxes with $\mathrm{NaCl}$ treatment were examined for $5 \mathrm{~min}$, after which the solution was replaced by hydrogen-rich $\mathrm{NaCl}$ solution as indicated by arrows. The mean ion fluxes within the measuring periods of $\mathrm{H}_{2}$-free or $\mathrm{H}_{2}$ treatment are shown in illustrations. (I, $\mathbf{K}$ and $\mathbf{M}$ ) Relative net ion fluxes of 5-7 samples under $150 \mathrm{mM} \mathrm{NaCl}$ treatment are shown. $* \mathrm{P}<0.05, * * \mathrm{P}<0.01$, $* * * * \mathrm{P}<0.0001$.

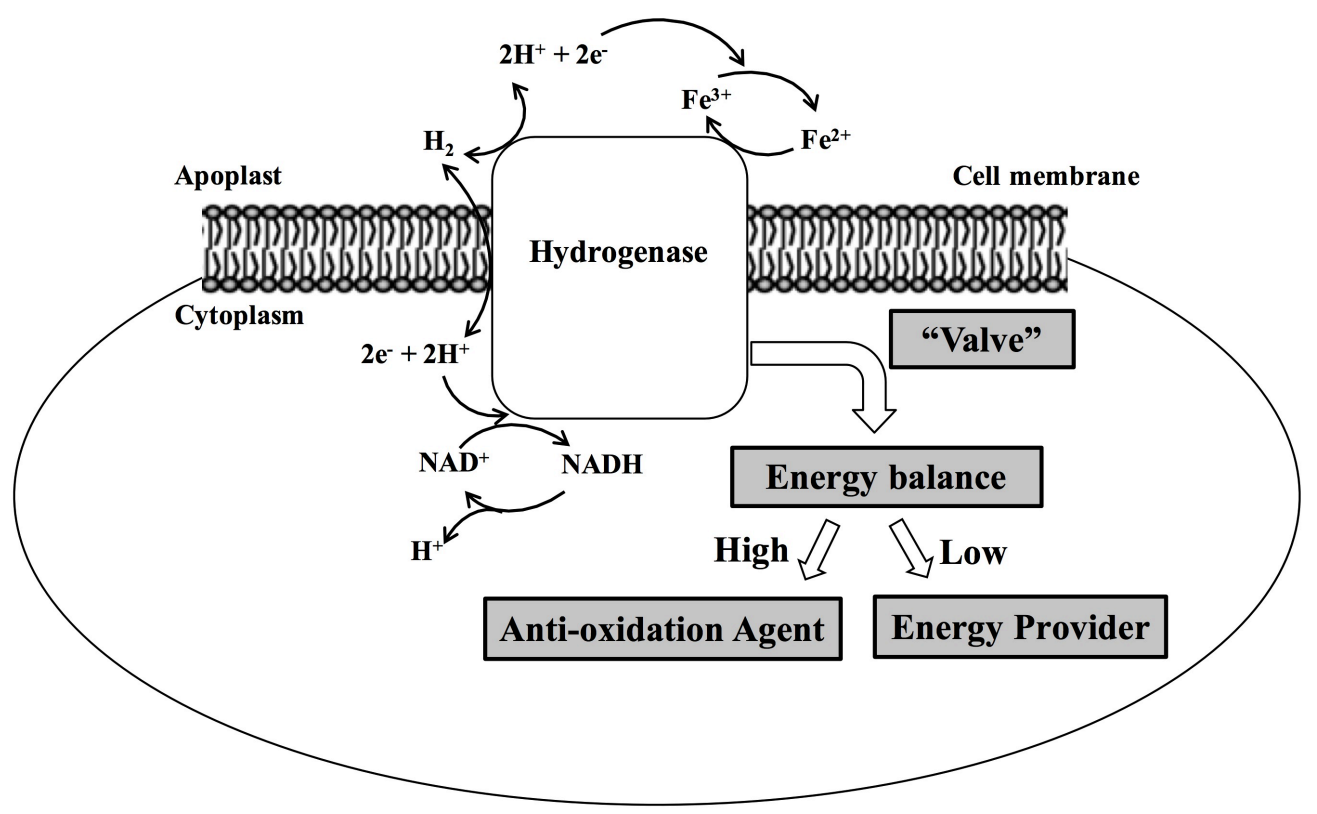

Figure 4 Hypothetical schematic diagrams of hydrogenase in higher plants PM 